\title{
Assessment of activities of daily living in patients post COVID-19: a systematic review
}

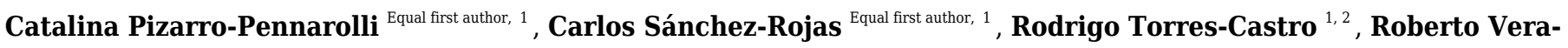 \\ Uribe $^{1,2}$, Diana C Sanchez-Ramirez ${ }^{3}$, Luis Vasconcello-Castillo ${ }^{1,2}$, Lilian Solís-Navarro ${ }^{1}$, Gonzalo Rivera-Lillo ${ }^{\text {Corresp. }}$ \\ $1,4,5$ \\ 1 Department of Physical Therapy, Faculty of Medicine, Universidad de Chile, Santiago, Chile \\ 2 International Physiotherapy Research Network (PhysioEvidence), Barcelona, España \\ 3 Department of Respiratory Therapy, College of Rehabilitation Sciences, University of Manitoba, Winnipeg, Canada \\ 4 Research and Development Unit, Clínica Los Coihues, Santiago, Chile \\ 5 Department of Neuroscience, Faculty of Medicine, Universidad de Chile, Santiago, Chile \\ Corresponding Author: Gonzalo Rivera-Lillo \\ Email address: gbrivera@uchile.cl
}

Background: Coronavirus disease has provoked much discussion since its first appearance. Despite it being widely studied all over the world, little is known about the impact of the disease on functional ability related to performing activities of daily living (ADL) in patients post COVID-19 infection.

Objectives: To understand the impact of COVID-19 on ADL performance of adult patients and to describe the common scales used to assess performance of ADL on patients post-COVID-19.

Methods: A systematic review was conducted. We included studies that applied a physical capacity test in COVID-19 patients, post-infection. Two independent reviewers analyzed the studies, extracted the data, and assessed the quality of the evidence.

Results: A total of 1,228 studies were included, after removing duplicates, 1,005 abstracts were screened and of those 983 were excluded. A final number of 9 studies which met the eligibility criteria were included. The findings revealed worsening of physical function and ADL performance in all patients post COVID-19 infection.

Conclusion: All included studies found a reduction of ADL beyond the test or scale used, revealing a vital worsening of functional ability in ADL performance and consequently loss of independence in COVID-19 patients after the acute phase of infection. Functional ability status previous to COVID-19 is crucial for predicting the severity of the disease and mortality. Barthel Index and ADL score were the most used assessment tools across subjects with different intrinsic capacity and context levels. 
2

3 Catalina Pizarro-Pennarollia, ${ }^{\text {, }}$, Carlos Sánchez-Rojas ${ }^{\mathrm{a},{ }^{*},}$, Rodrigo Torres-Castro ${ }^{\mathrm{a}, \mathrm{b}}$, Roberto Vera-

4

7 Affiliations:

Title: Assessment of activities of daily living in patients post COVID-19: a systematic review.

4

$$
\text { Uribe }^{\mathrm{a}, \mathrm{b}} \text {, Diana C Sanchez-Ramirez }{ }^{\mathrm{c}} \text {, Luis Vasconcello-Castillo }{ }^{\mathrm{a}, \mathrm{b}} \text {, Lilian Solís-Navarro }{ }^{\mathrm{a}} \text {, }
$$

$$
\text { Gonzalo Rivera-Lillo, d,e }
$$

aDepartment of Physical Therapy, Faculty of Medicine, Universidad de Chile, Santiago, Chile; bInternational Physiotherapy Research Network (PhysioEvidence), Barcelona, España; 'Department of Respiratory Therapy, College of Rehabilitation Sciences, University of Manitoba, Winnipeg, Canada; dDepartment of Neuroscience, Faculty of Medicine, Universidad de Chile,

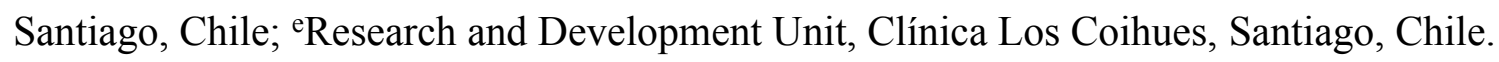

* Contributed equally as authors

Corresponding Author: Gonzalo Rivera-Lillo. Department of Physical Therapy, Faculty of Medicine, University of Chile, Santiago, Chile. Tel: +562 29786513. E-mail: gbrivera@uchile.cl.

Sources of funding: Rodrigo Torres-Castro is funded by a grant from the National Agency for Research and Development (ANID) / Scholarship Program / DOCTORADO BECAS CHILE / $2018-72190117$.

Disclosure statement: The authors declare no conflicts of interest 


\section{ORCID}

25 Catalina Pizarro-Pennarolli: https://orcid.org/0000-0002-0248-3312

26 Carlos Sánchez-Rojas: https://orcid.org/0000-0003-3832-1371

27 Rodrigo Torres-Castro: https://orcid.org/0000-0001-7974-4333

28 Roberto Vera-Uribe: https://orcid.org/0000-0003-4639-9574

29 Diana C Sánchez-Ramírez: https://orcid.org/0000-0003-1637-4309

30 Luis Vasconcello-Castillo: https://orcid.org/0000-0003-0405-3831

31 Lilian Solís-Navarro: https://orcid.org/0000-0003-3927-0094

32 Gonzalo Rivera-Lillo: https://orcid.org/0000-0002-8157-4086

33

34

35

36

37

38

39

40

41

42

43

44

45

46

Peer] reviewing PDF | (2020:11:55623:1:1:NEW 3 Feb 2021) 


\section{Abstract}

50 Background: Coronavirus disease has provoked much discussion since its first appearance.

51 Despite it being widely studied all over the world, little is known about the impact of the disease

52 on functional ability related to performing activities of daily living (ADL) in patients post COVID-

5319 infection.

54 Objectives: To understand the impact of COVID-19 on ADL performance of adult patients and

55 to describe the common scales used to assess performance of ADL on patients post-COVID-19.

56 Methods: A systematic review was conducted. We included studies that applied a physical

57 capacity test in COVID-19 patients, post-infection. Two independent reviewers analyzed the

58 studies, extracted the data, and assessed the quality of the evidence.

59 Results: A total of 1,228 studies were included, after removing duplicates, 1,005 abstracts were

60 screened and of those 983 were excluded. A final number of 9 studies which met the eligibility

61 criteria were included. The findings revealed worsening of physical function and ADL

62 performance in all patients post COVID-19 infection.

63 Conclusion: All included studies found a reduction of ADL beyond the test or scale used,

64 revealing a vital worsening of functional ability in ADL performance and consequently loss of

65 independence in COVID-19 patients after the acute phase of infection. Functional ability status

66 previous to COVID-19 is crucial for predicting the severity of the disease and mortality. Barthel

67 Index and ADL score were the most used assessment tools across subjects with different intrinsic

68 capacity and context levels.

69 Keywords: COVID-19; Activities of daily living; Rehabilitation; Systematic review 


\section{Introduction}

74 In December 2019 a SARS-COV-2 virus emerged in Wuhan, China, which has rapidly spread 75 around the world (Phelan, Katz and Gostin, 2020). In March 2020, the World Health Organization 76 (WHO) declared a global pandemic due to the disease caused by this novel coronavirus (COVID77 19) (Adhikari et al., 2020).

78

79 The magnitude of the sequelae produced by the disease at different functioning levels are still under research. The consequences, such as fatigue and breathlessness, have been reported to persist

81 after hospital discharge and the impact at different functioning levels over time remains unclear 82 (Carfí et al., 2020; Halpin et al., 2020). These findings are in line with the presence of symptoms 83 such as myalgia that has been reported in about $15 \%$ of patients four months post-COVID-19 84 infection (Garrigues et al., 2020).

85

86 The immediate and short-term assessment of physical capacity in patients with COVID-19 has 87 been a challenge, with a variable number of subjects being able to perform the tasks included on 88 the most commonly used physical capacity assessment tests (Belli et al., 2020; Curci et al., 2020; 89 Sakai et al., 2020; Liu et al., 2020; Bousquet et al., 2020; Zerah et al., 2020). In this way, it seems 90 necessary and reasonable to complement the clinical assessment of physical capacity with a further 91 analysis of functional ability related to perform activities of daily living (ADL). 
93 Impairments in body functions and structure, such as dyspnea, weakness, myalgia and other pain 94 sensations limit the ability to perform both basic ADL (BADL) and instrumental ADL (IADL). 95 BADL are related to personal care and mobility (such as dressing, eating, ambulating, toileting,

96 hygiene) whereas IADL is associated with the person's ability to interact with his/her environment.

97 Limitations in the ability to perform ADL increase the susceptibility to care dependency, reducing 98 the quality of life of both the affected person and the caregiver (Dunsky, 2019). Dependence tends 99 to be accentuated in the elderly population and through all age ranges after an extended ICU stay 100 (Herridge et al., 2016); a reduced level of ADL independence has been related to worse prognosis 101 after COVID-19 (Bousquet et al. 2020, Zerah et al. 2020).

102

103 The WHO consider two main aspects when defining functional ability. First, the intrinsic capacity 104 related to all the physical and mental capacities of an individual. Second, the environment related 105 to all the factors in the extrinsic world that form the context of an individual's life (WHO, 2015).

106 In this way, functional ability during ADL is determined by the impairment affecting the intrinsic 107 capacity as consequence of COVID-19, and the environment is determined by the context of each 108 individual's life, including variables such as the time course of the disease or the previous 109 functional status. Measuring ADL is relevant since it provides an essential framework of the 110 individual's current functional state, and thus the requirements for rehabilitation and other 111 resources (Rivera-Lillo et al., 2020).

113 Scales commonly used to assess functional status regarding ADL in inpatients and survivors of 114 critical illness are: Barthel Index (BI), Functional Independence Measure (FIM), Modified Rankin 115 Scale (mRS), EQ-5D, among others (Elliott et al., 2011). The mRS has been widely used as the 
116 primary outcome measure for acute stroke (Broderick, Adeoye and Elm, 2017), whereas FIM was

117 identified as a less biased assessment with greater reliability and validity compared to other

118 instruments (BI or Katz) (Cohen and Marino, 2000). Most of the scales allow quantification of the

119 magnitude of functional independence, based on the assistance requirements across different items

120 related to activities or participation during ADL.

121

122 The combination of variables leading to different scenarios related to intrinsic capacity and 123 environment places different limitations on ADL. It is therefore necessary to detect the best way

124 to know and understand functional ability during ADL before and after COVID-19. To fill this 125 knowledge gap, in this work we analyze the most common test reported to date to evaluate the 126 relationship between ADL functional ability and COVID-19. We also describe the factors related 127 to context and intrinsic capacity to provide an overview of the necessity to assess the impact of 128 COVID-19 in ADL limitations. Appropriate assessment scales will help to objectively evaluate 129 the effect of COVID-19 on the functional ability of patients over time, leading to optimal care and 130 rehabilitation strategies for affected subjects. At the same time, ADL functional ability status 131 previous to COVID-19 provides a fine-grained understanding of the importance of individual 132 context in the ADL functional status post-COVID-19. The aim of this report is to understand the 133 impact of COVID-19 on ADL performance of adult patients and to describe the common scales 134 used to assess ADL functional ability status on patients before and after COVID-19.

136 Materials \& Methods

137 We conducted a systematic review of the literature according to the Preferred Reporting Items for 138 Systematic Reviews and Meta-Analyses (PRISMA) guidelines (Moher et al., 2009). The review 
139 was registered in the International Prospective Register of Systematic Reviews (PROSPERO)

140 (CRD42020208449).

141

142 Criteria for considering studies in this review

143 We included randomized clinical trials (RCTs) and observational studies (cross-sectional,

144 longitudinal, case-control, and cohort) of adult patients with a confirmed diagnosis of COVID-19

145 published between 01/12/2019 and 10/09/2020. All editorials, reviews, clinical cases, and in vitro

146 studies were excluded. The studies included were aimed at assessing ADL after COVID-19

147 infection.

148

149 Search strategy

150 We reviewed the Embase, Cochrane Library, CINAHL, Web of Science, and PubMed/MEDLINE

151 databases on September 10, 2020 using the following search terms. For condition: SARS-CoV-2

152 OR COVID-19 OR 2019 novel coronavirus infection OR COVID19 OR coronavirus disease 2019

153 OR coronavirus disease-19 OR 2019-nCoV disease OR 2019 novel coronavirus disease OR 2019-

$154 \mathrm{nCoV}$ infection. For the main outcome: Functional capacity OR activities of daily living OR

155 Functional independence measure OR Barthel index OR Lawton Brody scale OR Katz index OR

156 ADL OR PCFS OR Functional scale OR Functional status (Supplementary file 1).

157

158 All references were exported to Rayyan Web software (Ouzzani et al., 2016); we then conducted

159 a bibliographic search and compiled the identified records and removed any duplicated studies.

160 Two authors (CSR and CPP) independently reviewed the information to extract data from the

161 included studies. All included studies were assessed for internal validity using a checklist. 
163 Reviewing procedure and study selection

164 The reviewing procedure was performed in two steps: 1) The titles and abstracts of all references

165 were reviewed by two investigators (CSR and CPP). Studies deemed not relevant based on the 166 review of the title and abstract were excluded. Conflicts were solved by a third reviewer (RTC).

167 2) The articles selected in the first step were read in full-text version and checked again using the 168 eligibility criteria (CSR and CPP). Any disagreements were solved by a third reviewer (RVU).

\section{Data extraction}

171 Two authors (CSR and CPP) extracted the data independently and in duplicate using a standardized

172 protocol and reporting forms. For each study, instruments, characteristics of the patients, main 173 outcome results, time of assessment, success in evaluation and conclusions were extracted. If any 174 relevant data were not in the article, the author was contacted to request the information.

\section{Risk of assessment}

177 The risk of bias and the quality of observational and interventional studies was assessed using the corresponding assessment tools recommended by the National Heart, Lung, and Blood Institute

179 (NHLBI, visited in September 2020). Each tool contains criteria against which internal validity and risk of bias are evaluated. The criteria were evaluated as 'Yes', 'No', or 'Other' (not reported, not applicable, or not determinable), and an overall rating was provided for each study based on the items rated with an affirmative answer: $\geq 75 \%=$ good, $50-75 \%=$ fair, $<50 \%=$ poor. Two

184 solved by arbitration by a third investigator (LVC). 


\section{Results}

187 The initial search found a total of 1,228 studies, 1,005 studies remained after removing duplicates. 188 After abstract and title screening, 983 studies were excluded. Twenty-one full texts remained, 189 which were assessed for eligibility leading to the exclusion of 12 studies due to wrong publication 190 type $(n=5)$, research protocol $(n=3)$, wrong study design $(n=2)$, incomplete data $(n=1)$, and preprint $191(n=1)$. The process was embodied in a flowchart (Figure 1). Nine studies (Halpin et al., 2020; Belli 192 et al., 2020; Curci et al., 2020; Sakai et al., 2020; Liu et al., 2020; Bousquet et al., 2020; Zerah et 193 al., 2020, Mcloughlin et al., 2020; Agarwal et al., 2020) met all the inclusion criteria. Four 194 retrospective (Belli et al., 2020; Sakai et al., 2020; Zerah et al., 2020; Agarwal et al., 2020), 2 195 prospective (Bousquet et al., 2020; Mcloughlin et al., 2020), 2 cross-sectional (Halpin et al., 2020; 196 Curci et al., 2020) and one RCT (Liu et al., 2020) studies were included. A total of 1,465 patients 197 were studied in the included articles. The median age was 68.98 years $( \pm 8.29)$ of which 716 $198(48.9 \%)$ were women. In total 1,190 (81.2\%) were inpatients (Table 1$).$

199

200 The included studies used different instruments such as BI (assesses BADL) (Belli et al., 2020; 201 Curci et al., 2020; Sakai et al., 2020), ADL score (assesses BADL and IADL) (Bousquet et al., 202 2020; Zerah et al., 2020), FIM (assesses BADL in motor and cognitive domain) (Liu et al., 2020), 203 Composite Functional Score (CFS) (assesses BADL and IADL) (Mcloughlin et al., 2020), mRS 204 (assesses disability in BADL and IADL) (Agarwal et al., 2020) and EQ-5D-5L (assesses BADL) 205 (Halpin et al., 2020). For each study, design, sample size, gender, age, body mass index, setting or 206 intervention and main patient characteristics were extracted (Table 1). 
208 A quality assessment was performed using the National Heart, Lung and Blood Institute's study 209 assessment tools. Six (66.6\%) of the nine studies included obtained a "Good" quality ranking with 210 a total score of over 75\% (Curci et al., 2020; Liu et al., 2020; Bousquet et al., 2020; Zerah et al., 211 2020; Mcloughlin et al., 2020; Agarwal et al., 2020) while three (33.3\%) of them pointed to a 212 "Fair" quality ranking with a total score of between 50\% and 75\% (Halpin et al., 2020; Belli et al., 213 2020; Sakai et al., 2020). No "Poor" quality ranked studies were included (Supplementary file 2). 214

\section{Main results}

216 Barthel Index

217 BI was assessed in three studies (Belli et al., 2020; Curci et al., 2020; Sakai et al., 2020). The main 218 objective was to assess functional ability (Belli et al., 2020) and assessment of early rehabilitation 219 programs for patients with COVID-19 (Curci et al., 2020; Sakai et al., 2020). Measures were 220 carried out on various occasions, such as on admission (Curci et al., 2020), discharge (Sakai et al., 221 2020) or both (Belli et al., 2020). The results of the studies showed low BI scores in this group of 222 patients, which is related to a worse level of functional ability. Belli et al. (2020) reported $67 \%$ of 223 patients with $<60$ points (poor score) on the BI, and $45.6 \%$ of patients who were bedridden when 224 admitted to a rehabilitation hospital. At discharge, the scores were significantly better with $47.5 \%$ of the patients still scoring poor on the BI, and only $17.5 \%$ who were still bedridden (Belli et al., 226 2020). Curci et al. (2020) exhibited differences in the scores of BI on higher and lower Fraction of 227 Inspired Oxygen (FiO2) patient groups, showing lower scores on the higher FiO2 group at ICU 228 discharge. Moreover, Sakai et al. (2020) indicated differences in mean scores regarding different rehabilitation groups (in-person vs. remote rehabilitation). The in-person rehabilitation group was 
230 significantly older, had more intubated individuals, and had worse mean scores at baseline and 231 discharge, 40 vs 70, respectively .

232

233 In contrast, the remote rehabilitation group had a higher mean BI at baseline and had no change 234 with the intervention, 90 vs 90, respectively. None of the 3 studies reported the results of each item 235 of the BI, except for Sakai et al., who reported mobility score. Together, these results show that BI 236 allows us to identify that a worse individual context is related to low ADL functional ability 237 previous to COVID-19 and is also related to a worse score post COVID-19. At the same time, BI 238 is able to detect the worsening in ADL in around $60 \%$ of subjects after COVID- 19.

239

240 ADL score

241 The ADL score tool was used in two studies to determine functional ability status in older patients 242 and the relationship with prognostic factors and mortality associated with COVID-19 (Bousquet 243 et al., 2020; Zerah et al., 2020). These studies focused on the ADL functional ability status at the 244 beginning of hospitalization. Six basic tasks related to BADL were assessed: bathing, dressing, 245 toileting, transfer, continence, and feeding. Zerah et al. (2020) reported a significant difference in 246 older patients with COVID-19 between survivors and non-survivors, with a median of 4.5 (IQR 247 2-6) and 3 (IQR 1-6) BADL respectively. Bousquet et al. (2020) showed that 50\% of patients had 248 altered at least 1 BADL, and also evaluated four IADL (using the telephone, transport, 249 medications, and money management) which showed that $63 \%$ of patients had altered at least 1 250 IADL. Results indicated that a decreased functional status and dependency in older patients were 251 associated with short-term mortality. In both studies, the score for each ADL was not reported. 
252 These results show that the ADL score can identify the impact of ADL functional ability status in

253 older patients and the negative outcomes related to high patient vulnerability.

254

255 Functional Independence Measure

256 FIM was assessed in one study to investigate the effects of respiratory rehabilitation on respiratory

257 function, ADL, QoL, and psychological status in elderly patients with COVID-19 who had been 258 discharged from hospital (Liu et al., 2020). The evaluation was carried out at discharge and at six 259 weeks in the post rehabilitation program. Older subjects with moderate or severe dementia, 260 previous neurological, respiratory or cardiovascular disease were excluded. Baseline Mean FMI 261 scores (pre-intervention) were around 109 (out of 126) for both groups. There was no significant 262 improvement post-intervention in the intervention group nor compared with the control group. 263 Results of each FIM item were not reported. In contrast to previous works, assessment of ADL 264 functional ability with FIM showed patients that require minimal assistance; the authors did not 265 find any improvement with the intervention.

266

267 Composite Functional Score

268 CFS was performed on one study to determine functional and cognitive outcomes among patients 269 with delirium in COVID-19 using a composite of the BI plus Nottingham Extended Activities of 270 Daily Living (NEADL) (Mcloughlin et al., 2020). The evaluation was carried out during hospital 271 stay and four weeks after delirium was ascertained. Results of CFS showed worse physical 272 function in post delirium patients ( 97 vs $153, \mathrm{p}<0.01$ ), but the results of each BI and NEADL item 273 were not reported. In this way, for COVID-19 hospitalized patients without delirium the CFS 
274 showed high values of independence after COVID-19. In contrast, in patients with delirium CFS

275 was able to detect poor functional ability outcomes (Mcloughlin et al., 2020).

276

277 Modified Rankin Scale

$278 \mathrm{mRS}$ was used in one study to correlate cerebral microbleeds and leukoencephalopathy with 279 clinical, laboratory, and functional outcomes in adult and elderly inpatients with COVID-19 280 (Agarwal et al., 2020). All patients reported worse functional ability in the mRS assessment, but 281 patients with leukoencephalopathy and/or cerebral microbleeds required longer ventilator support, 282 had longer hospitalization stays, and higher mRS scores at discharge compared with patients 283 without these magnetic resonance imaging findings. The higher $\mathrm{mRS}$ scores indicate overall worse 284 functional status on discharge. In this way, mRS assessment was able to detect worsening ADL 285 functional ability post COVID-19. Moreover, mRS detected differences in functional ability 286 related to other clinical variables related with the severity of the disease.

287

288

$E Q-5 D-5 L$

289 EQ-5D-5L was used in one of the included studies to assess the impact of pre- and post- COVID290 19-disease on each participant's mobility, personal care, usual activities, pain and 291 anxiety/depression 4 to 8 weeks after hospital discharge (Halpin et al., 2020). The results showed 292 a significant drop in EQ-5D-5L score in $68.8 \%$ of ICU patients and $45.6 \%$ in patients from other 293 wards. Patients presented a clinically significant decrease in EQ-5D-5L on average $48 \pm 10.3$ days 294 post discharge, which translated into worsened mobility, self-care, usual activities, 295 pain/discomfort, and anxiety/depression. These results show that the EQ-5D-5L is able to identify 
296 the impact of COVID-19 on ADL functional ability status after discharge. Also, EQ-5D-5L is able 297 to detect differences related to the severity of the disease.

298

299 Discussion

300 This review identified nine studies that assessed performance of ADL on COVID-19 patients using 301 eight different scales: BI (Belli et al., 2020; Curci et al., 2020; Sakai et al., 2020), ADL score 302 (Bousquet et al., 2020; Zerah et al., 2020), FIM (Liu et al., 2020), Composite Functional Score 303 (CFS) (Mcloughlin et al., 2020), mRS (Agarwal et al., 2020) and EQ-5D-5L. In these studies, the 304 performance of ADL on COVID-19 patients was mainly used to explore the association between 305 baseline functional ability as a mortality predictor (Bousquet et al., 2020, Zerah et al., 2020) and 306 to identify changes in functional ability outcomes after the acute period of infection (Mcloughlin 307 et al., 2020; Agarwal et al., 2020) (Table 2).

308

309 In this way, ADL assessment can be used to identify functional limitations, to understand the 310 patient's prognosis and to evaluate the intervention's effect on the subject. The majority of studies

311 included in this review evaluated ADL: 1) On admission to a rehabilitation unit, mostly as a 312 prognostic factor, and 2) At discharge and during the follow-up period, to evaluate the impact of 313 the disease but also to compare the progress obtained as result of an intervention or rehabilitation 314 process.

315

316 In all of the studies included, the findings revealed a decline in ADL performance after COVID-

31719 infection regardless of the scale applied. Those who had the worse results were older patients 318 and / or patients who had complications during their hospital stay, such as being admitted to ICU 
319 (Halpin et al., 2020), mechanical ventilation (Belli et al., 2020), delirium (Mcloughlin et al., 2020), 320 cerebral microbleeds, leukoencephalopathy (Agarwal et al., 2020) or greater oxygen requirements

321 (Curci et al., 2020). Participation in a rehabilitation program was also a factor likely to modify the

322 outcomes in functional capacity, however, not all cases were able to improve the performance of 323 ADL (Liu et al., 2020). Several factors regarding a patient's context are likely to affect the success, 324 or lack of it, in improving the functional capacity and ADL performance of the subjects. 325

Our results show the different tools used to evaluate functional abilities during ADL. However, 327 not all evaluate the same dimensions. Among the tools used are the BI and the FIM (Belli et al., 328 2020; Curci et al., 2020; Liu et al., 2020; Sakai et al., 2020). The BI assesses the performance in BADL, such as feeding, personal toileting, bathing, or dressing, with a score between 0 and 100 points (Bouwstra et al., 2019). A higher number reflects greater ability to function independently and has the advantage that it can be applied to self-reporting or direct administration (Bouwstra et al., 2019). The FIM assesses the functional status with scores which range from 18 (lowest) to 126 (highest), but there is a difference to BI, which in addition to BADL incorporates psychological and social functions as communication or special cognition (Maritz et al., 2019). Both instruments are widely used, particularly in patients with neurological conditions (Bouwstra et al., 2019; Maritz 336 et al., 2019).

337

The EQ-5D-5L is a variation of the EQ-5D, a standardized instrument for measuring generic health 339 status (Janssen et al., 2013). This instrument assesses the mobility, self-care, usual activities, 340 pain/discomfort and anxiety/depression, allowing the evaluation of BADL (Janssen et al., 2013).

341 The ADL score assesses washing, getting dressed, moving about indoors, going to the toilet, 
342 eating, and continence with scores ranging from 0 to 6 . A total score $\leq 5 / 6$ indicates ADL-

343 dependency (Burton and Potter, 2017). It is likely that the simplest test is the mRS, which measures

344 the degree of disability or dependence in the ADL of people who have suffered a stroke or other

345 causes of neurological disability (Broderick, Adeoye and Elm, 2017). However, it does not allow

346 precise discrimination of the dimensions affected when planning an intervention. On the other

347 hand, if a tool is not capable of meeting the clinician's requirements, composite tools can be used,

348 as was the case in one of the selected studies.

349

350 ADL performance acts as an indicator of a patient's prognosis (Bousquet et al., 2020; Zerah et al.,

351 2020; Level et al., 2018). Complementing rehabilitation efforts on ADL training may lead to a

352 major impact on the patient's life, rather than just considering physical function parameters (Elliott

353 et al., 2011). The importance of ADL as a prognostic factor can be seen in the present association

354 between dependence or low functional capacity with short- and medium-term mortality (Guidet et

355 al., 2020).

356

357 Another aspect related to independence level is cognitive performance, which can be included to 358 complement the assessment of ADL (Torres-Castro et al., 2020a). The cognitive sphere is 359 particularly relevant in IADL due to higher complexity invested on the involved tasks at all age 360 groups and particularly on elderly people. Therefore, tools such as the Mini-Mental State 361 Examination (MMSE) or Montreal Cognitive Assessment (MOCA) could complement ADL 362 evaluation. These tests are highly cost-effective since they are easy to implement by healthcare 363 professionals in all clinical settings. Other relevant variables to keep in mind for a more complete 364 patient assessment when COVID-19 survivors are comprehensively evaluated is respiratory 
365 function, quality of life and physical capacity (Torres-Castro et al., 2020a). In particular, we must

366 have a special focus on respiratory function, due to COVID-19 being mainly a respiratory disease

367 and which has reported sequelae in lung function after infection (Torres-Castro et al., 2020b). We

368 consider that these should be evaluated more exhaustively in further long-term studies.

369

370 Patients are out of their normal context during hospitalization, thus some ADL evaluations, 371 especially IADL, must be adapted or omitted according to the nature of the assessment. Therefore,

372 ADL evaluations should be completed once the patient is discharged and returns to his context so

373 that the impact of COVID-19 after the acute phase can be more accurately estimated. In addition

374 to the context, it becomes cardinal to select the adequate assessment tool to obtain accurate results

375 (Bai et al., 2020).

376

377 In the literature we find a specific tool to assess functional status, the Post-COVID-19 Functional

378 Status (PCFS) Scale, which could be used for patient follow-up (Klok et al., 2020). This scale

379 assesses the patient's functional capacity upon discharge from the hospital and allows functional

380 sequelae to be assessed. Although it does not strictly correspond to a test that evaluates ADL, its

381 information can be useful to complement the functional evaluation of these patients, especially

382 since studies have already appeared that have validated it in post-COVID-19 patients (Lorca et al., 383 2020).

384

385 In this work, we identified six tests used to explore the independence level during ADL to estimate

386 the impact in functional ability and the relationship with prognostic factors and mortality

387 associated with COVID-19. A key aspect of integrating information from different studies requires 
388 knowing the features of the sample related to intrinsic capacity and context described in each study.

389 Thus, in the studies, including subjects with severe intrinsic capacity impairment, most of the tests

390 are suitable for exploring the independence level during ADL, independently of the context. A

391 different scenario could be observed in studies conducted in a rehabilitation program context

392 (leading to selection bias). Liu et al. (2020) reported a higher level of independent functional ability

393 post COVID-19 in comparison with samples coming from studies conducted in other different

394 contexts not related to rehabilitation. In this way, the combination of intrinsic capacity and context

395 gives us valuable information which can be used to select the appropriate assessment tool.

396

397 Until specific instruments that assess ADL appear and are validated in post-COVID-19 patients,

398 we recommend the use of tools designed for this purpose, such as the BI, the FIM or the ADL

399 Score. Although the FIM did not show any discrimination in the effect of an intervention (Liu et 400 al., 2020), we recommend that future studies use the FIM in a population with greater functional 401 compromise. Further studies, including a deeper analysis of ADLs, both BADL and IADL, are 402 required to explore the impact of COVID-19 on functional performance among adults, especially 403 on elderly people.

404

405 Limitations and strengths

406 The limitations of this review were mostly related to the heterogeneity of the studies, including 407 patient characteristics, study design, methods, and assessment timeframe; in most of the studies 408 there is no detailed description of demographic and clinical features of the sample. Also, we 409 reviewed a small number of studies which only show short-term outcomes (long-term are 410 unknown), and ADL / functional performance were not the main aim of the studies. Another 
411 important limitation is that our results are based on articles where the mean age of people was over

41260 years old, so the findings cannot be extrapolated to people under that age. The main strength is 413 its focus on the assessment of ADL as an essential outcome to optimize future rehabilitation 414 protocols and resource allocation. Furthermore, it provides an overview of various assessment 415 tools that have been used to explore ADL among COVID-19 patients.

\section{Conclusions}

418 All included studies found a reduction of ADL despite the test or scale used, revealing a vital 419 worsening of physical function, deterioration of ADL performance and consequently loss of 420 independence of COVID-19 patients after the acute phase of infection. Besides, the functional 421 ability status previous to COVID-19 is vital for predicting the severity of the disease and mortality.

422 Considering the results shown in our work, the choice of the best test to assess ADL is closely 423 related to the intrinsic capacity and the subjects' context. Thus, Barthel Index and ADL score were 424 the most used assessments across subjects with different levels of intrinsic capacity and contexts.

426 Assessment of activities of daily living provide relevant information regarding the functional 427 impact on COVID-19 patients, which contributes towards identifying the rehabilitation needs of 428 this population and could inform the allocation of resources to support their recovery. 429

430 Well-designed studies should research short and long-term functional impact on post-COVID-19 431 patients with the objective of optimizing intervention strategies and supporting decision-making 432 in clinical practice. It is also essential to further test the psychometric properties of these tests on 
433 COVID-19 patients. The data collected to date in this systematic review is a useful starting point 434 for further studies.

435

436

437

438

439

440

441

442

443

444

445

446

447

448

449

450

451 References

452 Adhikari SP, Meng S, Wu Y-J, Mao Y-P, Ye R-X, Wang Q-Z, Sun C, Sylvia S, Rozelle S, Raat 453 H, Zhou H. 2020. Epidemiology, causes, clinical manifestation and diagnosis, prevention 454 and control of coronavirus disease (COVID-19) during the early outbreak period: a scoping review. Infectious diseases of poverty 9: 29. 
456

457

458

459

460

461

462

463

464

465

466

467

468

469

470

471

472

473

474

475

476

477

Agarwal S, Jain R, Dogra S, Krieger P, Lewis A, Nguyen V, Melmed K, Galetta S. 2020. Cerebral microbleeds and leukoencephalopathy in critically ill patients with COVID-19. Stroke 51: $2649-2655$.

Bai C, Chotirmall SH, Rello J, Alba GA, Ginns LC, Krishnan JA, Rogers R, Bendstrup E, Burgel PR, Chalmers JD, Chua A, Crothers KA, Duggal A, Kim YW, Laffey JG, Luna CM, Niederman MS, Raghu G, Ramirez JA, Riera J, Roca O, Tamae-Kakazu M, Torres A, Watkins RR, Barrecheguren M, Belliato M, Chami HA, Chen R, Cortes-Puentes GA, Delacruz C, Hayes MM, Heunks LMA, Holets SR, Hough CL, Jagpal S, Jeon K, Johkoh T, Lee MM, Liebler J, McElvaney GN, Moskowitz A, Oeckler RA, Ojanguren I, O'Regan A, Pletz MW, Rhee CK, Schultz MJ, Storti E, Strange C, Thomson CC, Torriani FJ, Wang X, Wuyts W, Xu T, Yang D, Zhang Z, Wilson KC. 2020. Updated guidance on the management of COVID-19: from an American Thoracic Society/European Respiratory Society coordinated International Task Force (29 July 2020). European Respiratory Review 29: 200287.

Belli S, Balbi B, Prince I, Cattaneo D, Masocco F, Zaccaria S, Bertalli L, Cattini F, Lomazzo A, Dal Negro F, Giardini M, Franssen FME, Janssen DJA, Spruit MA. 2020. Low physical functioning and impaired performance of activities of daily life in COVID-19 patients who survived the hospitalisation. European Respiratory Journal 56: 2002096.

Bousquet G, Falgarone G, Deutsch D, Derolez S, Lopez-Sublet M, Goudot FX, Amari K, Uzunhan Y, Bouchaud O, Pamoukdjian F. 2020. ADL-dependency, D-Dimers, LDH and absence of anticoagulation are independently associated with one-month mortality in older inpatients with COVID-19. Aging 12: 11306-11313.

Peer] reviewing PDF | (2020:11:55623:1:1:NEW 3 Feb 2021) 
478 Bouwstra H, Smit EB, Wattel EM, van der Wouden JC, Hertogh C, Terluin B, Terwee CB. 2019. 479 Measurement Properties of the Barthel Index in Geriatric Rehabilitation. Journal of the American Medical Directors Association 20: 420-425.e1.

481

482

483

484

485

486

487

488

489

490

491

492

493

494

495

496

497

498

499

Broderick JP, Adeoye O, Elm J. 2017. Evolution of the Modified Rankin Scale and its use in future stroke trials. Stroke 48: 2007-2012.

Burton JR, Potter JF. 2017. Screening tools for geriatric assessment by specialists. In Geriatrics for Specialists. Berlin: Springer, Cham. 81-88.

Carfì A, Bernabei R, Landi F, Gemelli Against COVID-19 Post-Acute Care Study Group. 2020. Persistent Symptoms in Patients After Acute COVID-19. Journal of the American Medical Association 324: 603-605.

Cohen ME, Marino RJ. 2000. The tools of disability outcomes research functional status measures. Archives of Physical Medicine and Rehabilitation 81: S21-9.

Curci C, Pisano F, Bonacci E, Camozzi DM, Ceravolo C, Bergonzi R, De Franceschi S, Moro P, Guarnieri R, Ferrillo M, Negrini F, de Sire A. 2020. Early rehabilitation in post-acute COVID-19 patients: data from an Italian COVID-19 rehabilitation unit and proposal of a treatment protocol. A cross-sectional study. European journal of physical and rehabilitation medicine 56: 633-641.

Dunsky A. 2019. The Effect of Balance and Coordination Exercises on Quality of Life in Older Adults: A Mini-Review. Frontiers in aging neuroscience 11: 318.

Elliott D, Denehy L, Berney S, Alison JA. 2011. Assessing physical function and activity for survivors of a critical illness: a review of instruments. Australian Critical Care 24: 155166. 
500 Garrigues E, Janvier P, Kherabi Y, Le Bot A, Hamon A, Gouze H, Doucet L, Berkani S, Oliosi E,

501

502

503

504

505

506

507

508

509

510

511

512

513

514

515

516

517

518

519

520

521
Mallart E, Corre F, Zarrouk V, Moyer JD, Galy A, Honsel V, Fantin B, Nguyen Y. 2020. Post-discharge persistent symptoms and health-related quality of life after hospitalization for COVID-19. Journal of Infection 81: e4-e6.

Guidet B, de Lange DW, Boumendil A, Leaver S, Watson X, Boulanger C, Szczeklik W, Artigas A, Morandi A, Andersen F, Zafeiridis T, Jung C, Moreno R, Walther S, Oeyen S, Schefold JC, Cecconi M, Marsh B, Joannidis M, Nalapko Y, Elhadi M, Fjølner J, Flaatten H; VIP2 study group. 2020. The contribution of frailty, cognition, activity of daily life and comorbidities on outcome in acutely admitted patients over 80 years in European ICUs: the VIP2 study. Intensive care medicine 46: 57-69.

Halpin SJ, McIvor C, Whyatt G, Adams A, Harvey O, McLean L, Walshaw C, Kemp S, Corrado J, Singh R, Collins T, O'Connor RJ, Sivan M. 2020. Post-discharge symptoms and rehabilitation needs in survivors of COVID-19 infection: a cross-sectional evaluation. Journal of medical virology 93: 1013-1022.

Herridge MS, Chu LM, Matte A, Tomlinson G, Chan L, Thomas C, Friedrich JO, Mehta S, Lamontagne F, Levasseur M, Ferguson ND, Adhikari NK, Rudkowski JC, Meggison H, Skrobik Y, Flannery J, Bayley M, Batt J, Santos CD, Abbey SE, Tan A, Lo V, Mathur S, Parotto M, Morris D, Flockhart L, Fan E, Lee CM, Wilcox ME, Ayas N, Choong K, Fowler R, Scales DC, Sinuff T, Cuthbertson BH, Rose L, Robles P, Burns S, Cypel M, Singer L, Chaparro C, Chow CW, Keshavjee S, Brochard L, Hebert P, Slutsky AS, Marshall JC, Cook D, Cameron JI; RECOVER Program Investigators (Phase 1: towards RECOVER); Canadian Critical Care Trials Group. 2016. The RECOVER program: disability risk groups 
522

523

524

525

526

527

528

529

530

531

532

533

534

535

536

537

538

539

540

541

542

543

544

and 1-year outcome after 7 or more days of mechanical ventilation. American journal of respiratory and critical care medicine 194: 831-844.

Janssen MF, Pickard AS, Golicki D, Gudex C, Niewada M, Scalone L, Swinburn P, Busschbach J. 2013. Measurement properties of the EQ-5D-5L compared to the EQ-5D-3L across eight patient groups: a multi-country study. Quality of life research 22: 1717-1727.

Klok FA, Boon GJAM, Barco S, Endres M, Geelhoed JJM, Knauss S, Rezek SA, Spruit MA, Vehreschild J, Siegerink B. 2020. The Post-COVID-19 Functional Status (PCFS) Scale: a tool to measure functional status over time after COVID-19. European Respiratory Journal. 56: 2001494.

Level C, Tellier E, Dezou P, Chaoui K, Kherchache A, Sejourné P, Rullion-Pac Soo AM. 2018. Outcome of older persons admitted to intensive care unit, mortality, prognosis factors, dependency scores and ability trajectory within 1 year: a prospective cohort study. Aging clinical and experimental research 30: 1041-1051.

Liu K, Zhang W, Yang Y, Zhang J, Li Y, Chen Y. 2020. Respiratory rehabilitation in elderly patients with COVID-19: A randomized controlled study. Complementary therapies in clinical practice 39: 101166.

Lorca A, Torres R, Ribeiro I, Benavente P, Pizarro M, San Cristobal B, Ugarte J, Laura C, Huanchicay C, Mamani, A. 2020. Linguistic validation and cross-cultural adaptation of the Post COVID-19 Functional Status Scale (PCFS) for the Chilean population. American Journal of Physical Medicine and Rehabilitation. doi: 10.1097/PHM.0000000000001706

Maritz R, Tennant A, Fellinghauer C, Stucki G, Prodinger B. 2019. The Functional Independence Measure 18-item version can be reported as a unidimensional interval-scaled metric: Internal construct validity revisited. Journal of rehabilitation medicine 51: 193-200. 
545 Mcloughlin BC, Miles A, Webb TE, Knopp P, Eyres C, Fabbri A, Humphries F, Davis D. 2020.

546 Functional and cognitive outcomes after COVID-19 delirium. European geriatric medicine

$547 \quad 11: 857-862$.

548 Moher D, Liberati A, Tetzlaff J, Altman DG, PRISMA Group. 2009. Preferred reporting items for 549 systematic reviews and meta - analyses: the PRISMA statement. Public Library of Science $550 \quad$ medicine https://doi.org/10.1371/journal.pmed.1000097.

551 National Heart, Lung and Blood Institute. Quality assessment tool for observational cohort and

552

553

554

555

556

557

558

559

560

561

562

563

564

565

566

567 cross - sectional studies. National Heart, Lung and Blood Institute. Available at https://www.nhlbi.nih.gov/health-topics/study-quality-assessment-tools.

Accessed September 25, 2020.

Ouzzani M, Hammady H, Fedorowicz Z, Elmagarmid A. 2016. Rayyan - a web and mobile app for systematic reviews. Systematic Reviews 5: 210.

Phelan AL, Katz R, Gostin LO. 2020. The Novel Coronavirus Originating in Wuhan, China: Challenges for Global Health Governance. Journal of the American Medical Association 323: 709-710.

Rivera-Lillo G, Torres-Castro R, Fregonezi G, Vilaró J, Puppo H. 2020. Challenge for Rehabilitation After Hospitalization for COVID-19. Archives of physical medicine and rehabilitation 101: 1470-1471.

Sakai T, Hoshino C, Yamaguchi R, Hirao M, Nakahara R, Okawa A. 2020. Remote rehabilitation for patients with COVID-19. Journal of Rehabilitation Medicine 52: jrm00095.

Torres-Castro R, Solis-Navarro L, Sitjà-Rabert M, Vilaró J. 2021. Functional Limitations PostCOVID-19: A Comprehensive Assessment Strategy. Archivos de bronconeumología 57 Suppl 1: 7-8. 
568 Torres-Castro R, Vasconcello-Castillo L, Alsina-Restoy X, Solis-Navarro L, Burgos F, Puppo H, 569 Vilaró J. 2020. Respiratory function in patients post-infection by COVID-19: a systematic 570 review and meta-analysis. Pulmonology https://doi.org/10.1016/j.pulmoe.2020.10.013

571 World Health Organization. 2015. World report on ageing and health 2015. Available at 572 https://www.who.int/ageing/events/world-report-2015-launch/en/ (accessed 25 January 573 2021).

574 Zerah L, Baudouin E, Pepin M, Mary M, Krypciak S, Bianco C, Roux S, Gross A, Toméo C, 575 Lemarié N, Dureau A, Bastiani S, Ketz F, Boully C, de Villelongue C, Romdhani M, 576 Desoutter MA, Duron E, David JP, Thomas C, Paillaud E, de Malglaive P, Bouvard E, 577 Lacrampe M, Mercadier E, Monti A, Hanon O, Fossey-Diaz V, Bourdonnec L, Riou B, 578 Vallet H, Boddaert J; APHP / Universities / Inserm COVID-19 research collaboration. 579 2020. Clinical Characteristics and Outcomes of 821 Older Patients with SARS-Cov-2 Infection Admitted to Acute Care Geriatric Wards. The journals of gerontology Series A, Biological sciences and medical sciences. https://doi.org/10.1093/gerona/glaa210.

582

583

584

585

586

587

588

589

590 
592 Figure legends

593 Figure 1. Flowchart of included studies

594 
Figure 1

Flowchart of included studies 

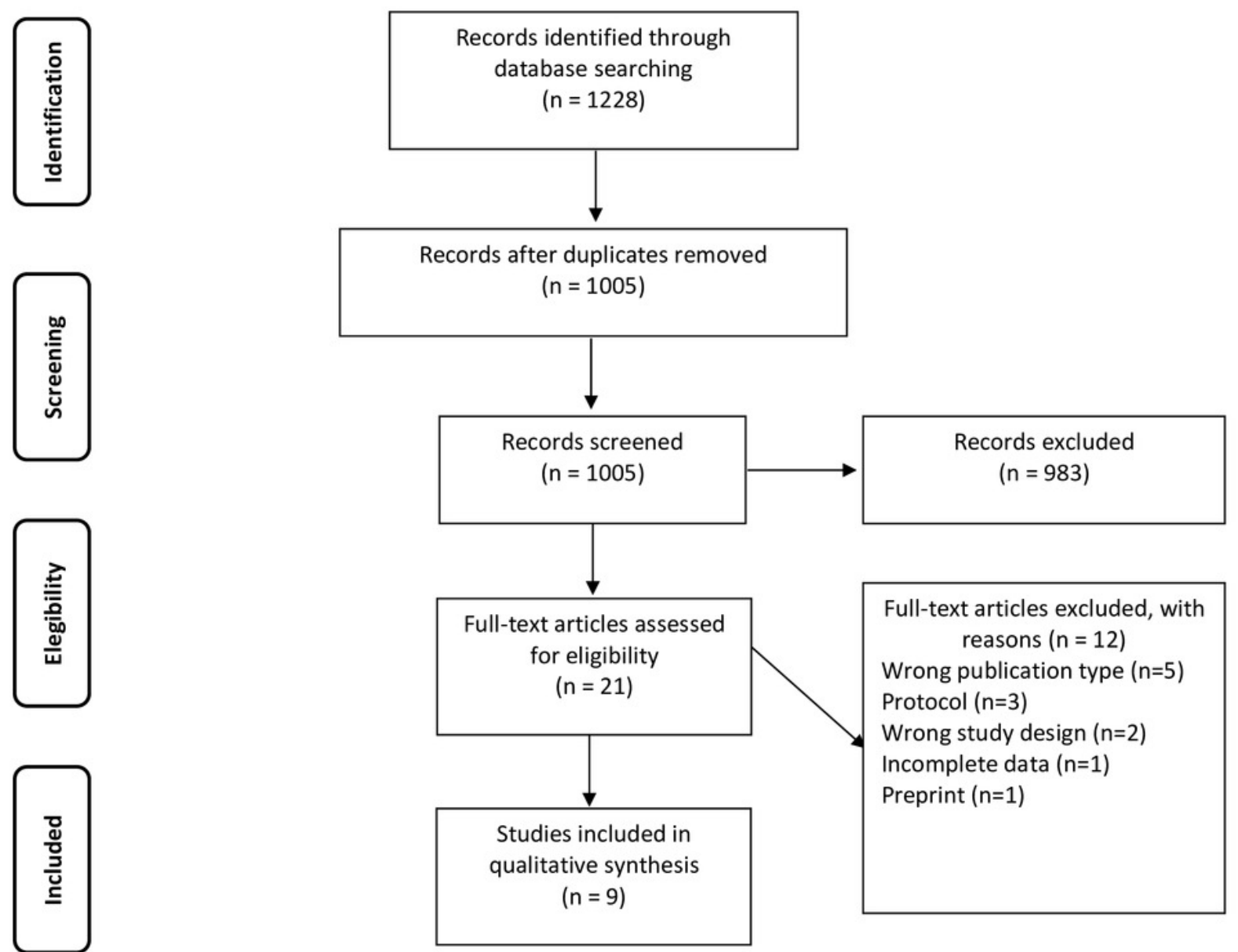
Table $\mathbf{1}$ (on next page)

Characteristics of included studies 
Table 1. Characteristics of included studies

\begin{tabular}{|c|c|c|c|c|c|c|}
\hline $\begin{array}{l}\text { Author, year } \\
\text { Country }\end{array}$ & Design & Participants (F/M) & Age (years) & $\begin{array}{c}\text { BMI / } \\
\text { Anthropometrics }\end{array}$ & Setting/Intervention & Patients characteristics \\
\hline $\begin{array}{l}\text { Liu K. et al } \\
2020 \\
\text { China }\end{array}$ & $\mathrm{RCT}$ & $\begin{array}{l}\text { CG: } 36(12 / 24) \\
\text { IG: } 36(11 / 25)\end{array}$ & $\begin{array}{l}\text { CG: } 68.9 \pm 7.6 \\
\text { IG: } 69.4 \pm 8.0\end{array}$ & $\begin{array}{l}\text { CG: } 22.9 \pm 3.9 \\
\text { IG: } 23.1 \pm 3.5\end{array}$ & Outpatients / RRP & $\begin{array}{l}\text { DLCO } \% \text { predicted CG: } 60.7 \pm 12.0 \\
\text { DLCO\% predicted IG: } 60.3 \pm 11.3 \\
\text { FEV1/FVC (\%): CG: } 60.44 \pm 5.77 \text {; IG: } 60.48 \pm 6.39 \\
\text { CT multilobar lesion } 48(66.6 \%) \\
\text { Comorbidities: HT: } 18(25 \%) \text {, DM: } 18(25 \%)\end{array}$ \\
\hline $\begin{array}{l}\text { Bousquet G. et } \\
\text { al, } 2020 \\
\text { France. }\end{array}$ & Prospective & $108(48 / 60)$ & $78 \pm 7.8$ & $\begin{array}{l}17(16 \%) \\
<21 \mathrm{~kg} / \mathrm{m} 2\end{array}$ & Inpatients / NI & $\begin{array}{l}\text { CT scan lung damage: } 82(76 \%) \text { mild } 21(19.4 \%) \text {, moderate } 35 \\
(32.4 \%) \text {, extensive } 20(28.5 \%) \text {, severe } 6(5.5 \%) \text {. Mortality rate: } 28 \\
(26 \%) \text {. } \\
\text { Comorbidities: HT }(71 \%) \text {, DM }(28 \%) \text {. }\end{array}$ \\
\hline $\begin{array}{l}\text { Sakai T. et al, } \\
2020 \\
\text { Japan. }\end{array}$ & Retrospective & $43(12 / 31)$ & $\begin{array}{l}65 \text { (range 21- } \\
95)\end{array}$ & NR & $\begin{array}{l}\text { Inpatients and } \\
\text { outpatients / RRG } \\
\text { vs DRG }\end{array}$ & $\begin{array}{l}\text { Required ventilation: } 12(27.9 \%) \text {, ECMO: } 1(2.3 \%) \text {, required } \\
\text { oxygen: } 22(51 \%) \text {, } \\
\text { asymptomatic or mild: } 9(20.9 \%)\end{array}$ \\
\hline $\begin{array}{l}\text { Zerah L. et al, } \\
2020 \text { France. }\end{array}$ & Retrospective & $821(476 / 345)$ & $86 \pm 7$ & NR & Inpatients / NI & $\begin{array}{l}\text { Severe at admission: } 107(13 \%) \text {, died: } 250(31 \%) \text {, discharged: } 159 \\
(19 \%) \text {, transferred to rehabilitation centers: } 365(45 \%), \geq 2 \\
\text { comorbidities: } \\
698(85 \%)\end{array}$ \\
\hline $\begin{array}{l}\text { Curci C. et al, } \\
2020 \\
\text { Italy. }\end{array}$ & Cross-sectional & $32(10 / 22)$ & $72.6 \pm 10.9$ & $24.7 \pm 2.4$ & $\begin{array}{l}\text { Rehabilitation unit / } \\
\text { Rehabilitation }\end{array}$ & $\begin{array}{l}\mathrm{FIO} 2 \geq 21 \% \text { and }<40 \%: 13(40.6 \%) \\
\mathrm{FIO} 2 \geq 40 \% \text { and }<60 \%: 19(59.4 \%)\end{array}$ \\
\hline $\begin{array}{l}\text { Belli S. et al, } \\
2020 \\
\text { Italy. }\end{array}$ & Retrospective & $103(50 / 53)$ & $73.9 \pm 12.9$ & $26.6 \pm 5.8$ & Inpatients / PR & $\begin{array}{l}\text { No MV: } 82(79.6 \%) \\
\text { NIV: } 9(8.7 \%) \text {, } \\
\text { MV and NIV: } 12(11.7 \%) \text {. } \\
\text { O2-supplementation: } 90(78.6 \%), \geq 2 \text { comorbidities: } 91(88 \%) \text {, and } \\
\geq 4: 57(55 \%)\end{array}$ \\
\hline $\begin{array}{l}\text { Mcloughlin } \\
\text { B.C. et al, } \\
2020\end{array}$ & Prospective & $71(18 / 53)$ & $\begin{array}{l}61 \text { (range } 24- \\
91)\end{array}$ & NR & Inpatients / NI & $\begin{array}{l}\text { Acute medical wards } 25(35.2 \%) \text {, } \\
\text { High Dependency Unit } 5(7 \%) \\
\text { Critical care } 41(57.7 \%)\end{array}$ \\
\hline
\end{tabular}




\begin{tabular}{|c|l|l|l|l|l|l|}
\hline U.K. & & & & & & \\
\hline $\begin{array}{c}\text { Agarwal, S. et } \\
\text { al, 2020 } \\
\text { U.S.A. }\end{array}$ & Retrospective & $115(33 / 82)$ & $63.5 \pm 8.6$ & $\begin{array}{l}\text { LCM: } 28.7 \pm 5.9 \\
\text { OMRIBF: } \\
27.4 \pm 6.1\end{array}$ & Inpatients / NI & $\begin{array}{l}\text { LCM patients 35 (30.4\%) required longer ventilator support and } \\
\text { were more likely to have a moderate and severe ARDS score. }\end{array}$ \\
\hline $\begin{array}{c}\text { Halpin, S.J. et } \\
\text { al, 2020 } \\
\text { U.K. }\end{array}$ & Cross-sectional & $100(46 / 54)$ & $\begin{array}{l}64,5 \text { (range 20- } \\
93)\end{array}$ & $\begin{array}{l}\text { OW-OB: } 59 \\
\text { HW: } 25 \text { UW: } 3 \\
\text { Unknown: } 11\end{array}$ & $\begin{array}{c}\text { Outpatients } \\
\text { (discharge)/ NI }\end{array}$ & $\begin{array}{l}\text { ICUP group: } 32(32 \%) \\
\text { WP group: 68 (68\%) }\end{array}$ \\
\hline
\end{tabular}

Data are shown as Mean $\pm \mathrm{SD}$, Median (Inter-quartile range), $\mathrm{n}(\%)$

Abbreviations. ARDS: Acute Respiratory Distress Syndrome; CG: control group; CT: Computed tomography; DLCO: Diffusing Capacity of the Lungs for Carbon Monoxide; DM: diabetes mellitus; DRG: direct rehabilitation group; ECMO: Extracorporeal Membrane Oxygenation; FEV1: Forced expiratory volume at 1 s; FIO2: Fraction of inspired oxygen; FVC: Forced vital capacity; HT: hypertension; HW: Healthy weighted; IG: intervention group; ICUP: intensive care unit patients; LCM: Leukoencephalopathy and/or Cerebral Microbleeds; MV: Mechanical Ventilation; NI: no intervention; NR: not reported; NIV: Non Invasive Mechanical Ventilation; OMRIBF: Other Magnetic Resonance Imaging Brain Findings; OB: obese; OW: Overweighted; PR: Pulmonary Rehabilitation; RCT: randomized controlled trial; RRG: remote rehabilitation group; RRP: Respiratory rehabilitation program; UW: Underweighted; WP: ward patients. 
Table 2 (on next page)

Findings of included studies 
Table 2. Findings of included studies

\begin{tabular}{|c|c|c|c|c|c|}
\hline Author, Year & Instrument & Results & $\begin{array}{l}\text { Time } \\
\text { assessment }\end{array}$ & $\begin{array}{l}\text { Success in the } \\
\text { evaluation, } \mathrm{n} \\
(\%)\end{array}$ & Conclusions \\
\hline Liu K. et al, 2020 & FIM & $\begin{array}{l}\text { Pre-Intervention: } \\
\text { FIM score CG: } 109.3 \pm 10.7 \text {; IG: } 109.2 \pm 13 \\
\text { Post-intervention: } \\
\text { FIM score CG: } 108.9 \pm 10.1 \text {; IG: } 109.4 \pm 11.1\end{array}$ & $\begin{array}{l}\text { Before and after } \\
\text { pulmonary } \\
\text { rehabilitation }\end{array}$ & $72(78.2 \%)$ & $\begin{array}{l}\text { Six-week respiratory rehabilitation can improve respiratory function, } \\
\text { QoL, and anxiety, but does not improve the FIM score of elderly } \\
\text { patients with COVID-19. }\end{array}$ \\
\hline $\begin{array}{l}\text { Bousquet G. et al, } \\
2020\end{array}$ & ADL Score & $\begin{array}{l}\text { ADL score } \leq 5 / 6: 54(50 \%) \\
\text { IADL score } \leq 3 / 4: 68(63 \%)\end{array}$ & $\begin{array}{l}\text { Before } \\
\text { hospitalization }\end{array}$ & $108(90 \%)$ & $\begin{array}{l}\text { ADL-dependency before hospitalization, serum levels of D-Dimers } \\
\text { and LDH, and the absence of anticoagulation were the factors } \\
\text { independently associated with one-month mortality in older inpatients } \\
\text { with COVID-19. }\end{array}$ \\
\hline $\begin{array}{l}\text { Sakai T. et al, } \\
2020\end{array}$ & $\mathrm{BI}$ & $\begin{array}{l}\text { RRG: BI mobility score } 15 \text {; total score } 90 \\
\text { DRG: BI mobility score } 10 \text { (range } 0-15 \text { ); total } \\
\text { BI score } 70 \text { (range } 0-85 \text { ) }\end{array}$ & $\begin{array}{l}\text { At hospital } \\
\text { discharge } \\
\text { (before and } \\
\text { after } \\
\text { rehabilitation) }\end{array}$ & $43(97.7 \%)$ & $\begin{array}{l}\text { Both mobility and total BI scores improved in both groups after } \\
\text { intervention. }\end{array}$ \\
\hline $\begin{array}{l}\text { Zerah L. et al, } \\
2020\end{array}$ & ADL Score & $\begin{array}{l}\text { Mean ADL score } 4 \text { (IQR2-6) } \\
\text { ADL score (Non-survivors) } 3 \text { (IQR 1-6) } \\
\text { ADL score (Survivors) } 4.5 \text { (IQR 2-6) }\end{array}$ & $\begin{array}{l}\text { During hospital } \\
\text { stay }\end{array}$ & $821(93.5 \%)$ & Hospital mortality was associated with lower ADL scores $(\mathrm{ADL}<4)$ \\
\hline $\begin{array}{l}\text { Curci C. et al, } \\
2020\end{array}$ & BI & $\begin{array}{l}\text { Total BI score: } 45.2 \pm 27.6 \\
\text { FIO2 } \geq 21 \% \text { and }<40 \%(\mathrm{n}=13) \\
\text { BI score } 53.3 \pm 29.3 \\
\text { FiO2 } \geq 40 \% \text { and }<60 \%(\mathrm{n}=19) \\
\text { BI score: } 39.6 \pm 25.7\end{array}$ & $\begin{array}{l}\text { At admission to } \\
\text { the } \\
\text { Rehabilitation } \\
\text { Unit }\end{array}$ & $32(88.8 \%)$ & COVID-19 patients had severe disability. Only 14 were able to walk. \\
\hline $\begin{array}{l}\text { Belli S. et al, } \\
2020\end{array}$ & BI & $\begin{array}{l}\text { At entry rehabilitation institute: } 67 \%: \leq 60 \mathrm{BI} \\
\text { score } \\
\text { At discharge rehabilitation institute: } 47.5 \%: \leq 60 \\
\text { BI score }\end{array}$ & $\begin{array}{l}\text { At entry and } \\
\text { discharge of } \\
\text { rehabilitation } \\
\text { institute }\end{array}$ & $103(89.5 \%)$ & $\begin{array}{l}\text { Physical functioning and performance of ADLs were still } \\
\text { significantly impaired at discharge to their home. }\end{array}$ \\
\hline Mcloughlin BC. & CFS & Pre Delirium: 153/166 CFS score & During hospital & $71(86.59 \%)$ & Delirium was associated with functional \\
\hline
\end{tabular}




\begin{tabular}{|l|l|l|l|l|l|}
\hline et al, 2020 & Post Delirium: 97/166 CFS score & $\begin{array}{l}\text { stay and four } \\
\text { weeks after } \\
\text { hospital } \\
\text { discharge }\end{array}$ & impairments in the mid-term. \\
\hline $\begin{array}{l}\text { Agarwal, S. et al, } \\
2020\end{array}$ & mRS & $\begin{array}{l}\text { LCM: 5 (IQR 4-5) mRS score } \\
\text { OMRIBF: 4 (IQR 2-5) mRS score }\end{array}$ & $\begin{array}{l}\text { At hospital } \\
\text { discharge }\end{array}$ & $115(100 \%)$ & $\begin{array}{l}\text { LCM was associated with critical illness, mortality and worse } \\
\text { functional outcome in patients with COVID-19. }\end{array}$ \\
\hline $\begin{array}{l}\text { Halpin, SJ. et al, } \\
2020\end{array}$ & EQ-5D-5L & $\begin{array}{l}\text { 22ICUG participants (22\%) experiencing new } \\
\text { problems in mobility, self-care or usual } \\
\text { activities. }\end{array}$ & $\begin{array}{l}\text { Mean 48 } 10.3 \\
\text { days post } \\
\text { hospital } \\
\text { discharge }\end{array}$ & $100(100 \%)$ & $\begin{array}{l}\text { COVID-19 was associated with illness-related fatigue, breathlessness } \\
\text { and psychological distress leading to a significant drop in quality of } \\
\text { life. }\end{array}$ \\
\hline
\end{tabular}

Abbreviations: ADL: Activities of daily living; BI: Barthel Index; CFS: Composite Functional Score; CG: control group; CT: computerized tomography; DRG: direct rehabilitation group; FIM

Functional Independence Measure; IADL: Instrumental Activities of daily living; ICUG: Intensive care unit group; IG: intervention group; IQR: Inter-quartile range; LCM: Leukoencephalopathy and/ or Cerebral Microbleeds; LDH: Lactate Dehydrogenase; mRS: Modified Rankin Scale; NI: no intervention; NR: not reported; OMRIBF: Other Magnetic Resonance Imaging Brain Findings; qSOFA: quick Sequential Organ Failure Assessment score; RRG: remote rehabilitation group. 